\title{
General Theory of Walkability as criteria for regenerating Maadi as a walkable neighborhood
}

\author{
Mariam, A , Abdullah ${ }^{1}$, Zeinab, Y, Shafik ${ }^{2}$ and Dalila,Y, El-Kerdany ${ }^{2}$
}

\begin{abstract}
:
Although Maadi neighborhood managed to keep some of its old magic and is more or less still considered as one of Cairo's most attractive, walkable and prestigious neighborhood, yet it gained some of the characteristics of the current great city of Cairo; where high rise buildings and traffic have recently appeared which led to the decline of the street's social life in most of Maadi's streets and the harmony of its urban design. Unfortunately the streets that used to formulate the urban design of Maadi and manipulated its historical value, livability and its sociability, lost its intimate scale, and became a more service road, without any kind of public life . Moreover, walking habits disappeared over the diminishing of walking streets that were replaced with wider roads for cars. Thus, the paper seeks to study the problems facing walkability in Maadi as a model of one of the most pedestrian and child friendly neighborhood in Cairo, and exploring the merits of the new urban theories methods and approaches followed in the developed countries such as the General Theory of Walkability; that is addressing the different aspects of walkability to enhance the urban harmony in the inner cities. Accordingly, the paper proposes selecting criteria to demarcate the areas that could be transferred into walkable ones, to be applied on Maadi, as picking the most suitable areas, would act as a catalyst to foster walkability to the rest of the neighborhood, and preserve the urban fabric of Maadi.
\end{abstract}

Keywords: Walkability, Maadi neighborhood, urban harmony, general theory of walkability

\footnotetext{
${ }^{1}$ Faculty of Engineering, Architecture Department, The American University in Cairo

${ }^{2}$ Faculty of Engineering, Architecture Department, Cairo University
} 


\section{Introduction:}

In the modernism times, traditional streets were deteriorated by the challenge of the growth of car use in the beginning of the $20^{\text {th }}$ century; as the main planning concept then was a separation between living, working, services and traffic, which led to losing a great deal of social interaction that used to take place there. Streets became empty of pedestrians, so increasingly becoming unsafe and the public realm was less attractive, uncomfortable, full of pollution and community instability ,leading to the declining of the inner-city of old neighborhoods . Consequently, in the developed countries an interest arose in preserving the inner cities in the 80s and 90s with a more focus on rehabilitating the social life in the public space, which would consequently preserve the urban fabric [1].

Thus, a huge volume of theories and decisions were introduced such as the general theory of walkability in 2012 to enhance the pedestrian friendly environment and foster walkability in the old downtowns and inner cities. This new theory encouraged walking over driving and controlled the urban sprawl by limiting the use of cars, which subsequently saved the urban design of the old districts and enhanced the quality of life of the residents.

However, in the meantime in Egypt, in the beginning of the $20^{\text {th }}$ century, European urban form and buildings of the new part of Cairo was more encouraged and intensified by the technological changes through the industrial revolution. Noting that, with mechanization in public transport, the new electric tram system encouraged the building of suburban residential quarters in the first years of the twentieth century, such as: Garden City along the Nile, Heliopolis to the north of the city, and Maadi near the hot spot springs resort of Helwan to the south. Nevertheless, developers built Garden City and Maadi as gardens and pedestrian friendly suburbs like their fashionable ones in Britain [2].

It is worth mentioning that, Maadi was initially planned as a green paradise, and one of the most walkable areas of Cairo. It has a special and unique urban character, with green areas along its streets, in addition to its distinguished upper class housing. People used the streets and the public spaces as an important part of their everyday life, and the public open spaces were filled of all kinds of social activities and regular habits; Maadians used to have many daily habits related to walking and strolling since it was first built. Noting that its growth was carefully monitored; no haphazard urban sprawl was possible with its specific building regulations. Moreover, in 2010 the neighborhood was documented as an area with special value to be preserved by The National Organization for Urban Harmony (NOUH). Yet, this special and harmonic urban fabric is facing a massive decay decades ago, and has been distorted and deformed to fulfill the demands of cars and other motor vehicles.

\section{The General Theory of Walkability}

According to the American urban planner Jeff Speck, "Walkability is a useful way to assess the characteristics of an area or a route, although it can be subjective". The theory explains the main elements and rules of walkability to be effective and successful if applied, which would help in revitalizing the socio economic aspect 
and encouraging people to socialize and use to streets as public space instead of car tubes and service roads .It explains how the pedestrian friendly and walkability environment should be based on. According to his studies; a walk has to satisfy four main conditions: it must be useful, safe, comfortable, and interesting. Each of these qualities is essential and none alone sufficient. These four conditions are mostly a method of thinking about a series of specific rules that are further organized into what is called the Ten Steps of Walkability .Together, they add up to a complete prescription for making our cities more walkable and pedestrian friendly, as follows:

\section{The useful walk}

Step 1: Put Cars in Their Place.

Step 2: Mix the uses

Step 3: Get the Parking Right,

Step 4: Let Transit Work,

The safe walk

Step 5: Protect the Pedestrian,

Step 6: Welcome Bikes,

The comfortable walk

Step 7: Shape the Spaces;

Step 8: Plant Trees,

\section{The interesting walk}

Step 9: Make Friendly and Unique Faces,

Step 10: Pick Your Winners, cities must make a conscious choice about the size and location of their walkable cores, to avoid wasteful walkability resources in areas that will never invite pedestrians [3]. Therefore, creating selecting criteria for demarcating the best area to start the procedures with is very important to ensure successful results.

\section{General criteria for selecting the study area to be walkable}

The general criteria for choosing the applied study area in old neighborhoods have been generated based on the above mentioned theory to fulfill the physical, social, physiological and environmental requirements in order to enhance the street life and preserve the harmonic urban planning as follows:

\subsection{Physical aspect:}

\subsubsection{The comfortable Walkable boundaries}

Locating the local facilities in the walkakble neighborhoods design is considered one of the most important physical aspects and principles, which is based on a considerable body of research clarifying that it should be within 400 meter of walking distance which equals to 5 minutes of walking. [4]. Also according to Barton, Grant \& Guise [5], the accepted threshold for walking to local facilities is 400 meter while 800 meter is a suggested threshold for walking to a town Centre. However, based on a planning report on a special development area in the Malaysian context; the comfortable walking distance differs ;for the elderly and preschoolers the maximum distance is 190 meter, for primary school children the 
distance is between 191 meter to 380 meter, for teenagers and adults the maximum distance is from 381 meter to 600 meter [6].

As for the walking distance to the nearest public transport station such as bus or train; guidelines often use $400 \mathrm{~m}$, or multiples such as $800 \mathrm{~m}$, as key distances in network and service planning, such as the Service planning guidelines for Sydney (NSW Ministry of Transport2006) which specify that $90 \%$ of households should be within $400 \mathrm{~m}$ of a rail line and/or bus route during the day, and within $800 \mathrm{~m}$ of a rail line and/or bus route at night time [7]. Accordingly, one can conclude that most studies looking at bus stop spacing use 400-meter service areas around bus stops, while around the public transit or rail stations widely use maximum of the 800 meter. Thus the chosen area radius will be maximum 800 meter including metro line.

However, based on walkability index, street network and connectivity is measured by the number of street intersections in a neighborhood. A higher value indicates more intersections and a greater degree of connectivity enabling more direct travel between two points using existing streets and pathways. [8]

\subsubsection{Social And Physiological aspect:}

Other important point that influences the criteria of selecting the study area targeting the social and physiological aspect is based on the ten steps of walkability by Speck within the four conditions of walkable communities, as follow:

- The area should be interesting with many valuable buildings, where sidewalks are lined by unique architectural buildings with deep frontages and friendly faces, as pedestrians must be entertained otherwise they will choose to drive.

- Safety and security should be achieved by choosing an area with small block sizes, as cities with the smallest blocks and small lanes are the ones best known for walkability; the more blocks per square mile, the more choices a pedestrian can make, and this would give a chance to the pedestrians against being hit by cars. However, Big block, with multi-lane system results in streets that are both harder to cross and easier to speed on. Moreover, the area should be applicable of achieving mixed use with day and night surveillance, where streets must feel safe not only be safe. Nevertheless, bikes requirements should be considered in the chosen area, as cities with more bicycles are much safer for both bicyclists and pedestrians. A Street with bikes once the drivers get used to them, is a place where cars proceed more cautiously and slowly.

- The area should be useful, where most aspects of everyday life are located close at hand and distributed in a way that walking serves them well, while demoting the car to its proper role, and setting parking minimums and outlawing private parking lots. As walkable areas should rely completely on the public transit.

- Urban form is likely to play a greater role in the choice to walk, as it has to be comfortable, meaning that buildings and landscape shape the urban streets into outdoor living rooms, which usually attract pedestrians and 
enhance the social bond. People enjoy open spaces and the great outdoors, yet they also enjoy, and need, a sense of enclosure. Not to mention that streets should be lined with green spaces and trees, which in addition to providing shades, they are also keys to pedestrian comfort and urban livability in so many different ways [3].

\subsubsection{Environmental aspect:}

The study area should include trees as mentioned above, which are usually essential, for pedestrian comfort, and they do slow drivers down a bit. They can also stop a car that has jumped on the curb. For that reason, the safest sidewalks are lined by both parked cars and trees. Additionally, street trees reduce ambient temperatures in hot weather, absorb rainwater and tailpipe emissions, and limit the effects of wind. Trees also improve the sense of enclosure by necking down the street space with their canopies. A consistent cover of trees can go a long way toward making up for an uninteresting walk. Street trees have been associated with significant improvements in both property values and retail viability, which increase the economy of the area in addition to fostering the social aspect and encourage people to walk again [9].

\section{Problems facing walkability in Maadi Neighborhood}

\subsection{Car invasion}

At the end of 1905, there were around 110 motorized vehicles in Cairo. Also, about 50 motorcycle sidecars and two Dietrich type omnibuses belonging to the newly formed Cairo Omnibus Company. Yet, still no signs of new roads linking Egypt's main cities, at least none that could serve motor vehicles. With everyone becoming car crazy, drastic changes befell Cairo's streets, sometimes entailing the razing of trees as roads were widened and asphalted to accommodate the new vehicles. New roads were laid out linking most of the country's cities and towns [10]. By 1930 more than 3000 all category vehicles licensed in Egypt and bridge builders from all over the world were invited to submit their tenders [11].

Not to mention that, in Maadi there is inadequate infra-structure in most of the streets and unsuitable pedestrian walkways with no cycling lanes, this makes cyclists and pedestrians neither safe nor satisfied. Moreover pedestrians are discouraged to choose walking and cycling as a usable alternative, where most of the sidewalks are not leveled, with broken pavement that causes many injuries for pedestrians and cyclists. Unfortunately the old streets of Maadi are witnessing today a terrible sense of loss and disappointment, as runaway cars, belching buses, insistent street vendors, taxi drivers, minibuses and toktoks are invading old streets and landscapes, leading to urban distortion [10].

\subsection{Pollution}

In the Cairo Air Improvement Project (CAIP), a Source-Attribution-Study (SAS) was conducted between 1997 and 2004 to identify the contribution of various sources to air pollution in Egypt. The study revealed that vehicle exhaust accounted for $32 \%$ of air pollution indicated by particle matter (PM10 and PM2.5) in air. This also implies the high contribution with other contaminants, which in the case of vehicle exhausts are emitted with fine particle matter. The study also exposed the 
myth that natural sources of sand and soil dust were the primary culprit and indicated how the transport sector is a priority in addressing air pollution.

And since in 2013, the total number of licensed vehicles in Egypt were 7.04 million vehicles, and about half of them are in the capital, Greater Cairo, and approximately half of all vehicles in Egypt are cars, specifically 3.83 million cars, thus this high percentage of private cars with its pollutant effect affect badly and robustly the health of the pedestrians and the materials of old buildings, which could lead to a rapid deterioration of the old valuable buildings. These pollutants create problems on the local scale, and are also transported in the air over long distances [12]. The construction of more roads with tunnels and bridges in response to the traffic congestion in the planning paradigm that is followed in Cairo generally and in Maadi specifically causes the mobility problems that we are facing nowadays. This motor vehicle-oriented solution leads to other problems in terms of environmental pollution by increasing the number of motor vehicles, accordingly increasing both carbon emissions and traffic accidents [13].

\subsection{Parking}

Parking problems, together with car exhaust fumes added to a misuse and a lack of maintenance of buildings and sidewalks. Adding on that, one of the most pivotal problems of walking and cycling in Maadi is parking especially the free ones. Based on (Soup,2005) parking worsens air quality ,speeds global warming, increases energy consumption ,raises the cost of housing, decreases public revenue, undermines public transportation, increases traffic congestion, damages the quality of the public realm ,escalates suburban sprawl, threatens historic buildings, weakens social capital, and worsens public health. However, a crucial side effect on historical areas and on urban heritage is that adaptive reuse and rehabilitation of historic properties can be discouraged, because there isn't sufficient space to create parking required for the buildings' new uses. Also free parking makes it too easy for people to spread out, encouraging forms of developments that are inherently wasteful and damaging, that are car oriented, which encourage driving over walking and cycling [14].

\subsection{Safety\& security}

According to (WHO 2009) ; almost half of the world's annual road traffic fatalities of approximately 1.3 million people are pedestrians, cyclists, and motorcyclists, and more than $90 \%$ occur in developing countries. In low-income countries, a large majority of deaths are not the vehicle occupants but the road users, consisting of pedestrians, bicyclists, two wheelers, and other small vehicles. Moreover, according to the World Bank website, pedestrians account for $65 \%$ of the fatalities out of the 1.17 million traffic related deaths around the world, with $35 \%$ of these being children [15]. Also there are still many dangerous and unsafe means of transportation in Maadi that threaten pedestrian life; such as microbus, toktok and old (unmaintained and deteriorated) public buses.

Moreover, in some streets and areas, street sexual harassment become a major problem for females in Egypt in general and in Maadi particularly, not to mention that the social acceptance of females riding bicycles or walking specially at night is 
mostly low, leads to reducing the percentage of female cyclists which is extremely rare and in many areas not present at all, as they have to face comments or even physical harassment, which can lead to crimes, accidents and several injuries [16]. Considering that, this violence has an indirect societal impact that generates a climate of fear, insecurity and an inclined superiority of male upon socialization in public spaces. However, if the social relations between users of the space are broken, then its success as a safe social space is welling to fail [17].

\subsection{Stray dogs}

Recently, based on the researcher observation; street stray dogs gathered in troops around the food leftovers and in secondary streets especially with closed shops or quite activity at night, along with fleets of cars instead of pedestrians, caused fear for people on foot either trying to cross the street or just walking. The presence of dogs caused great concern to pedestrians who were worried about their physical safety in Maadi streets. It is worth mentioning that, the local authorities in Maadi once launched an initiative for transferring the commercial street number 9 which is very livable into Pedestrian Street on Fridays, yet the initiative failed. One of the reasons of the failure is the existence of stray dogs in the street. Furthermore, while pedestrians trying to avoid the dogs around the corners and on the pavements, this exposing them to the risk of going down the pavement near the cars speeding on the street, which is noted to be an unsafe action.

Nevertheless, one may say that although all the risks and challenges faced walkability in the magnificent urban of Maadi, fortunately the neighborhood managed to keeps some of its pedestrians and cyclists. As the neighborhood still has some of its amenities close and some zones maintain their original urban harmony, which makes it easier to be revitalized again into a walkable and sociable neighborhood as it used to be decades ago. The potential for walking and cycling lies in a city's historical development; because surprisingly many of the major neighborhoods and districts that today are packed with cars actually have a past as cities of bicycles like Maadi neighborhood.

\section{Applying the proposed selecting criteria on Maadi}

In this regard the following section will be applying the proposed selecting criteria on Maadi, to learn how to demarcate the most winner quarter to be walkable, acting as a nucleus for revitalizing the whole neighborhood, as follows:

\subsection{The Physical aspect}

As mentioned earlier the local facilities in the comfortable walkable neighborhood should be located within 400 meter of walking distance that equals 5 minutes of walking, and maximum of 800 meter for the walking distance to the nearest public transport station such as bus or train according to the international guidelines , which equals 5-20 minutes. Thus, since Maadi has a metro line linking the whole neighborhood together, and the commercial street number 9 is considered the most old and popular street in Maadi with many services and cafes for entertainment, therefor the radius of 800 meters, will be including the metro line and street number 9, which has the potential to be walkable since it was once transferred into pedestrian street as shown in (figure 1). Therefore, four radiuses of 800 meters 
were selected as different alternatives covering most of the old neighborhood, including the metro line and street no.9 to choose afterwards the most convenient and suitable one among them, based on the rest of the criteria .

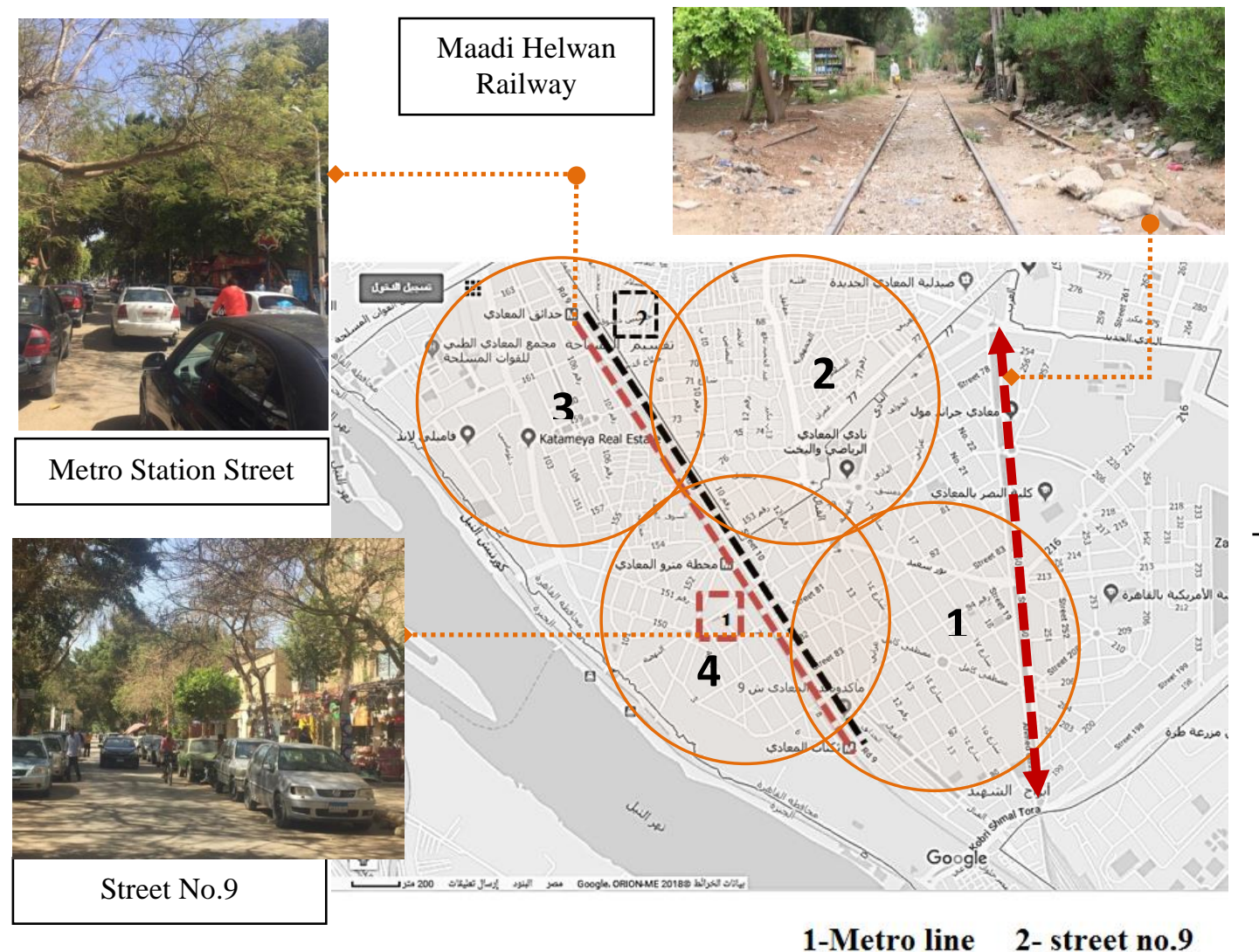

Figure 1 shows the metro line and street number 9 within 4 alternatives of the walkable areas

(Reference: Researcher, 2019)

As for street network and connectivity, it is achieved, as there is a worthy number of street intersections in the focus study area, that indicates a greater degree of connectivity enabling more direct travel between the streets using existing streets and pathways, as shown in (figure 2). 


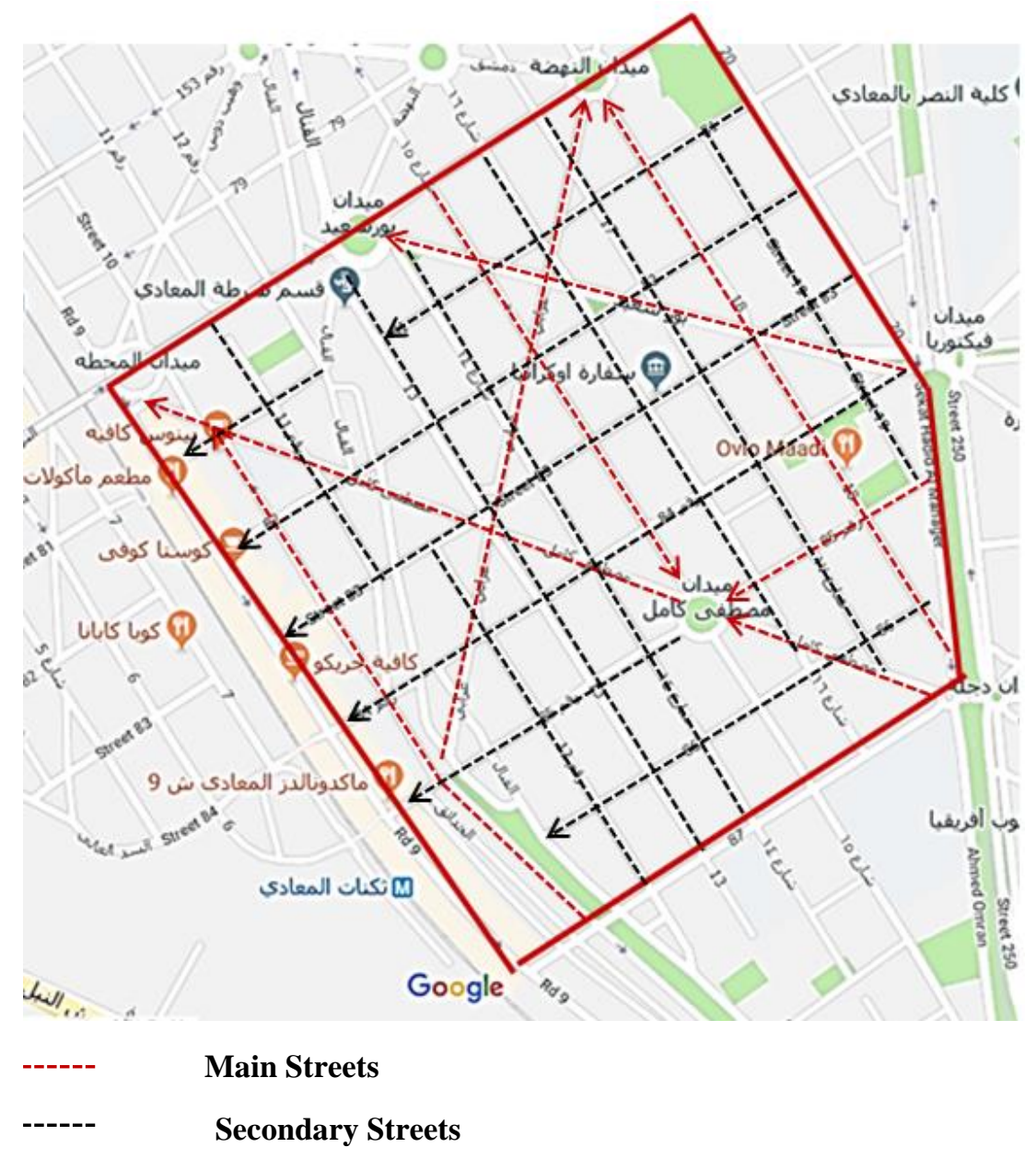

Figure 2 shows the high level of connectivity between the streets in the focus study area

(Reference: researcher, 2019)

\subsection{Social and physiological aspects:}

- Interesting: the oldest streets and square in Maadi are Sekat Hadid Al Mahager street, the commercial street number 9 , Mostafa Kamel street, which has many valuable architectural buildings, and its sidewalks are lined by unique buildings and green spaces along with friendly faces, as shown in figure (3\&4). Accordingly they contain the most historical villas and residential buildings in the neighborhood, as shown in (figures 5 \&6). 


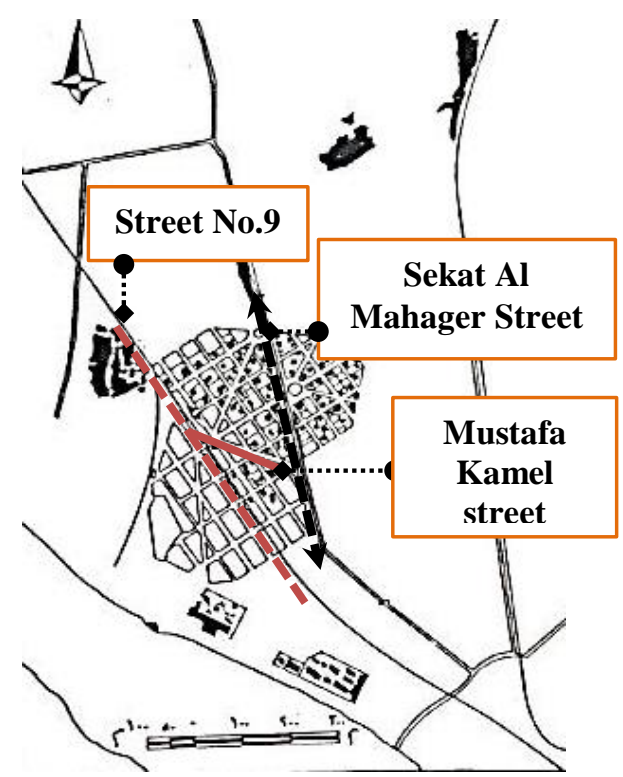

Figure 3 shows the oldest streets in Maadi in 1920

(Reference: Manal Khalil, 1997)

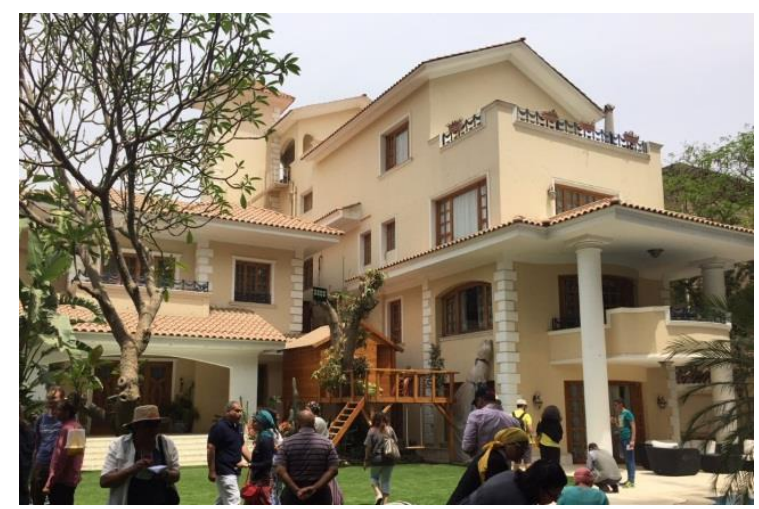

Figure 5 shows the garden of an oldvilla in Mustafa Kamel Street (Reference: Researcher,2017)

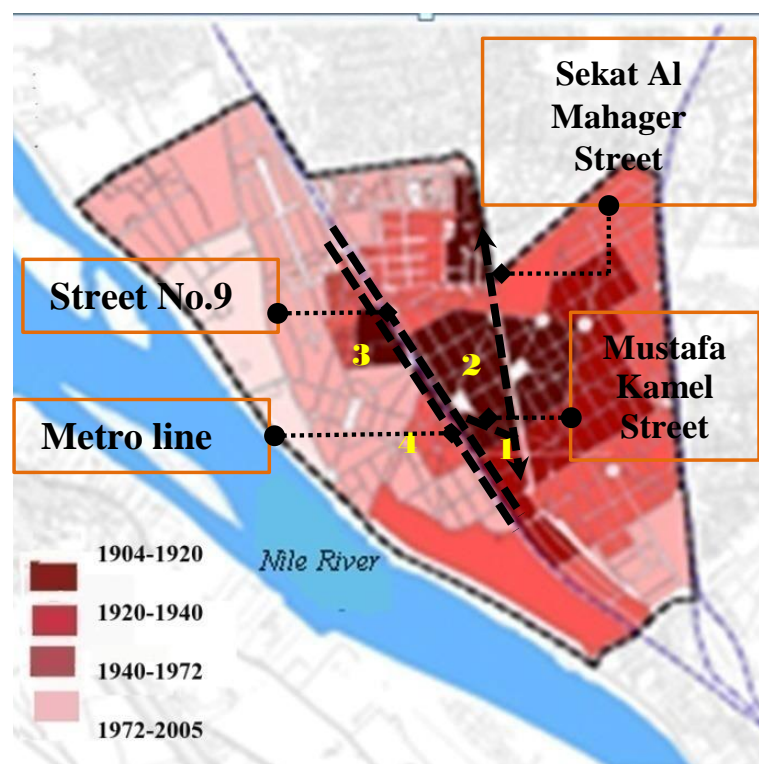

Figure 4 shows the historical development of Maadi district (Reference: N. Mahmoud\& P. Selman, 2010)

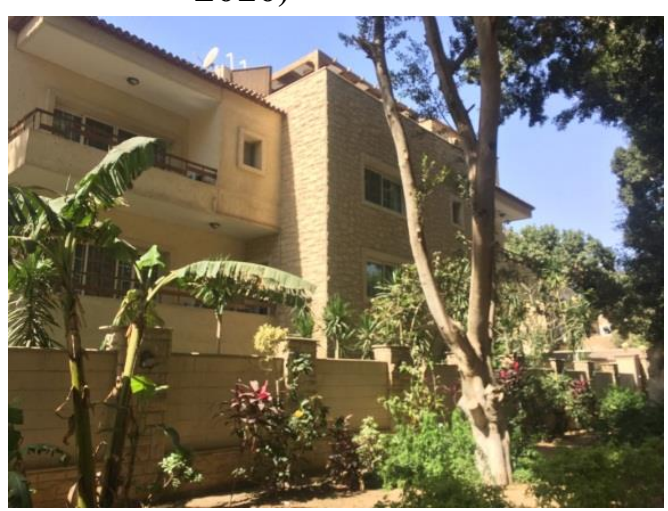

Figure 6 shows the exterior of an old villa in Mustafa Kamel Street (Reference: Researcher,2019)

Moreover, according to (NOUH) NATIONAL ORGANIZATION FOR URBAN $H A R M O N Y$, they settled the boundaries of the historical areas in Maadi that should be protected into three categories, the heights protected area is in Degla and Sarayt El Maadi areas which also includes the oldest Sekat Al Mahager Street, Mustafa Kamel street /square, Street no.9 in addition to the metro line, as shown in (figure 7). 


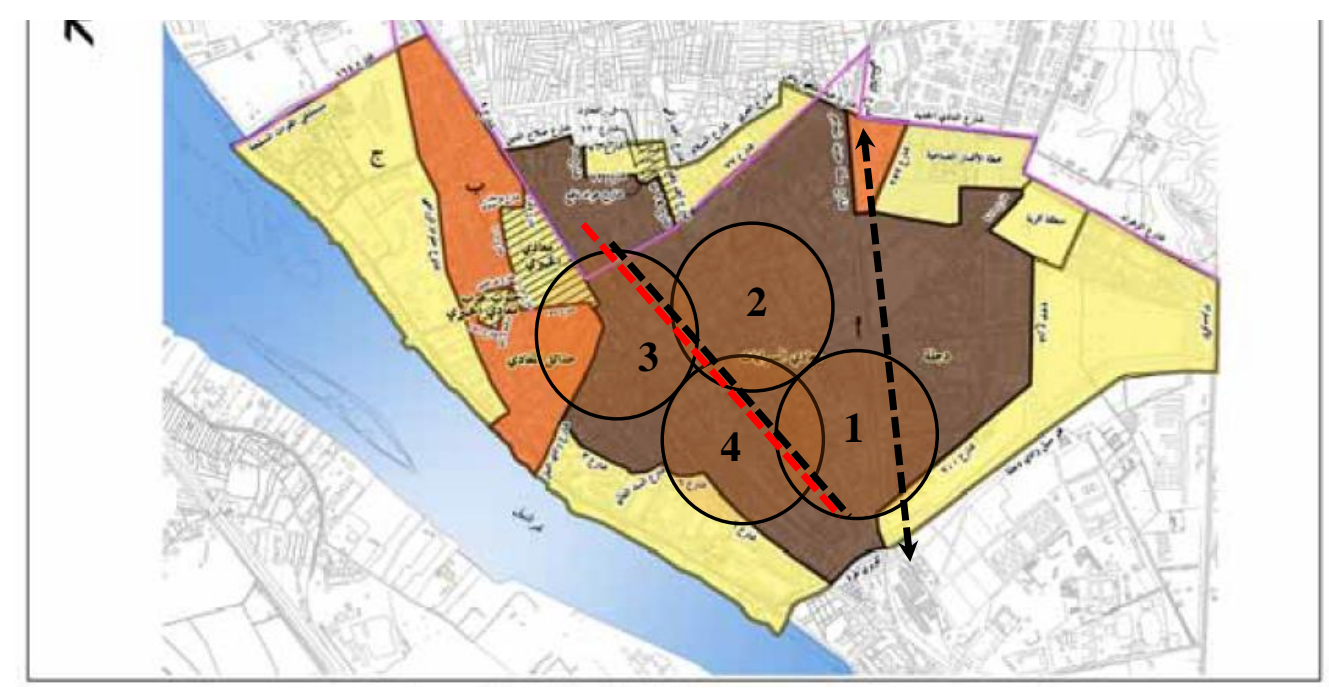

Figure 7 Shows the boundaries of the protected areas in Maadi, where the highest valuable areas in the brown shade

(Reference: National Organization for Urban Harmony, 2010)

Accordingly, in this regard this narrowing down the choices into one; that would include the most historic buildings according to NOUH with the oldest streets ( Mustafa Kamel, Sekat Al Mahagar Street, street No.9), Mustafa Kamel square and the metro line as a service transit. Thus the chosen study area would be number 1 as shown in (figures 8\&9).

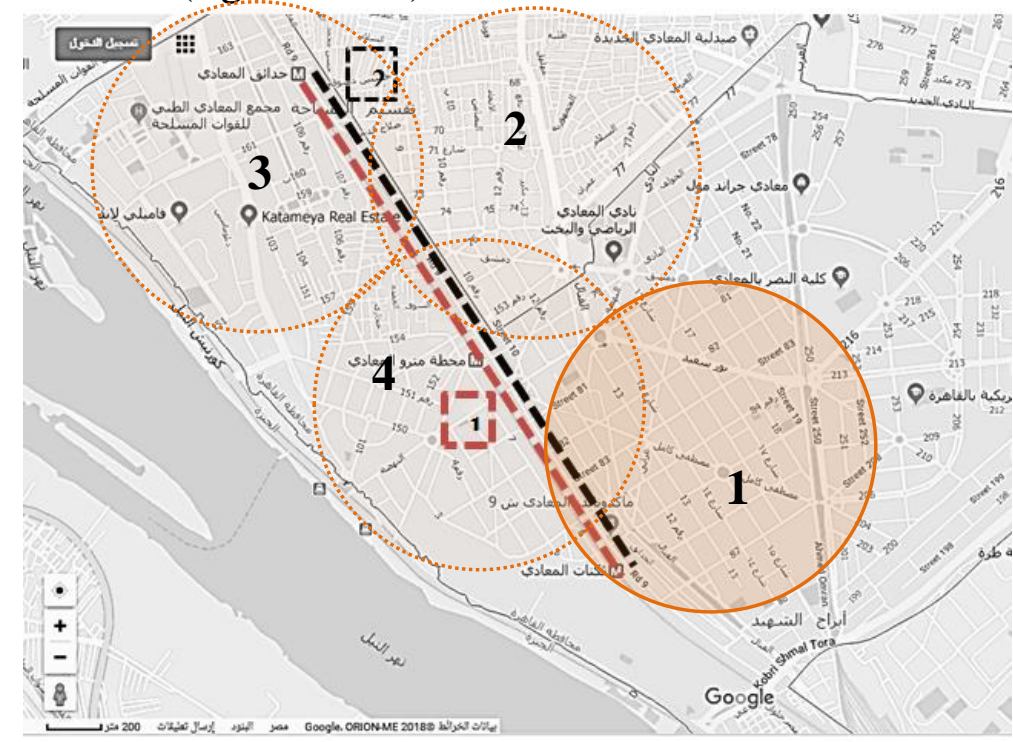

Figure 8 shows the chosen study area (Reference: researcher,2019)

1-Metro line

2- street no. 9 


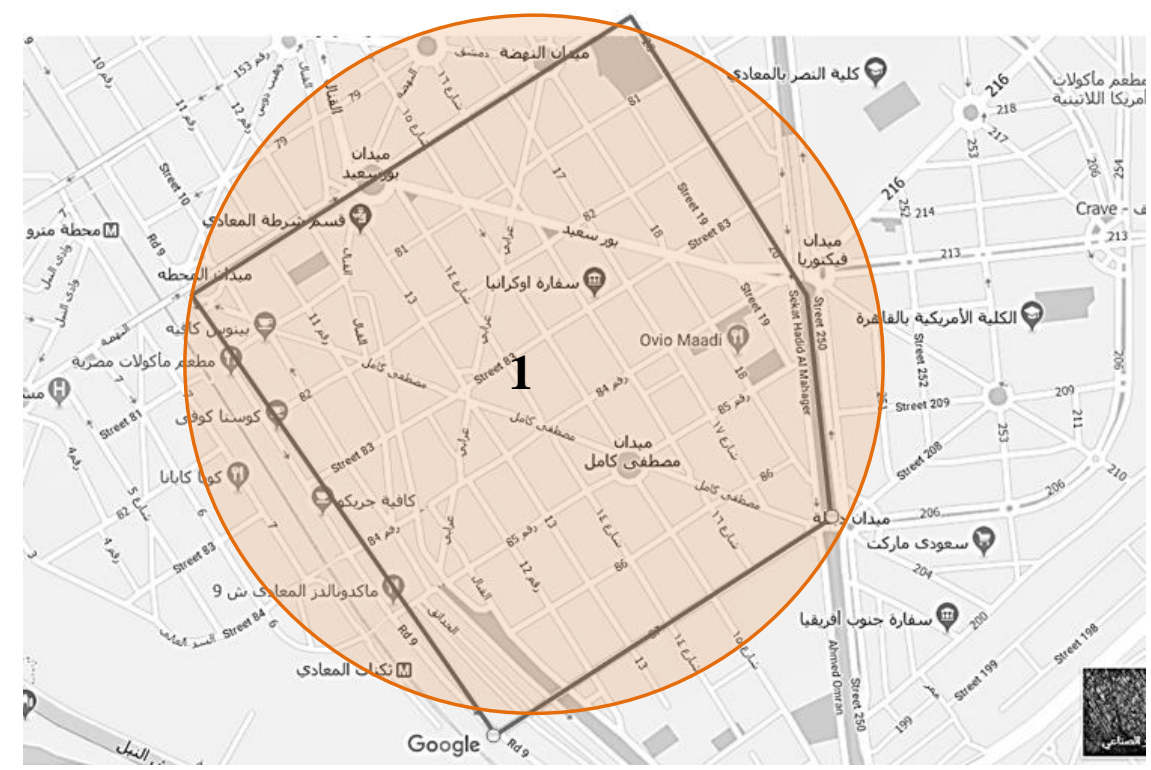

Figure 9 shows the boundaries of the chosen study focus area (Reference: researcher,2019)

- Safety: the above chosen area has many services, embassies, landmarks, some food facilities and special public buildings in addition to school, as shown in (figure 10), which achieves the day and night surveillance and securing the area. Moreover, the area is distinguished with small blocks, which are the ones best known for walkability, with small lane widths, and low car speed due to the existence of school and that most of the area is residential buildings, which makes driving less necessary, and bikers can cycle there without the fear of being hit by cars, providing safe environment, as shown in (figures $11 \& 12$ ).

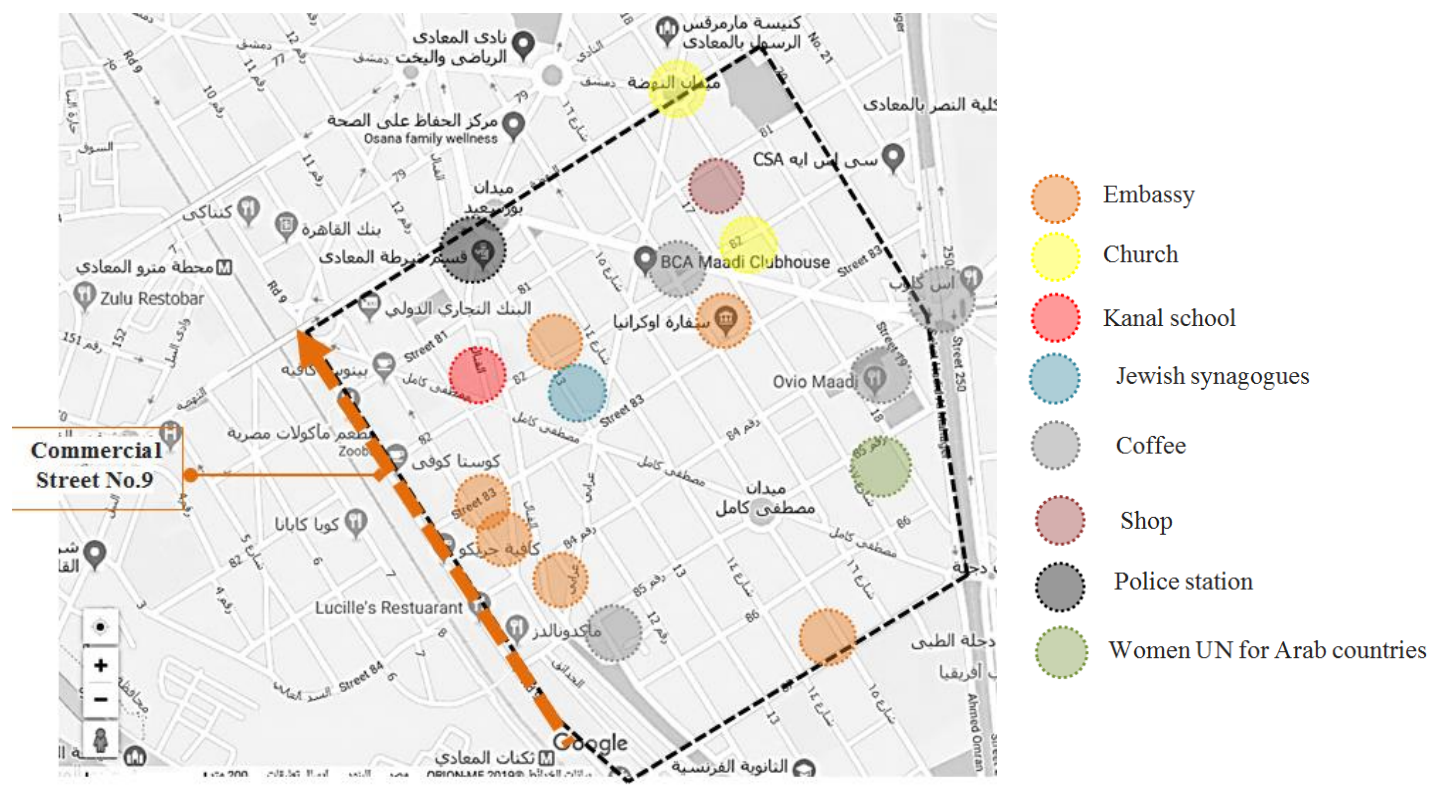

Figure 10 shows the landmarks and special services in the area (Reference: researcher, 2019) 


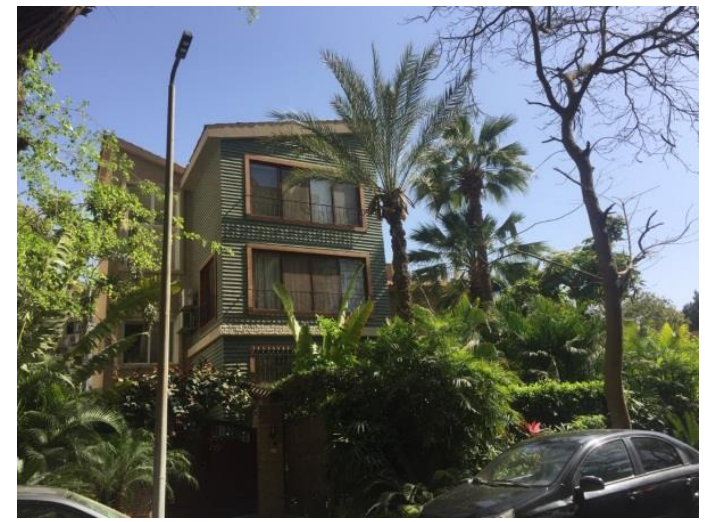

Figure 11 shows the small block size buildings in Mustafa Kamel Street (Reference: researcher, 2019)

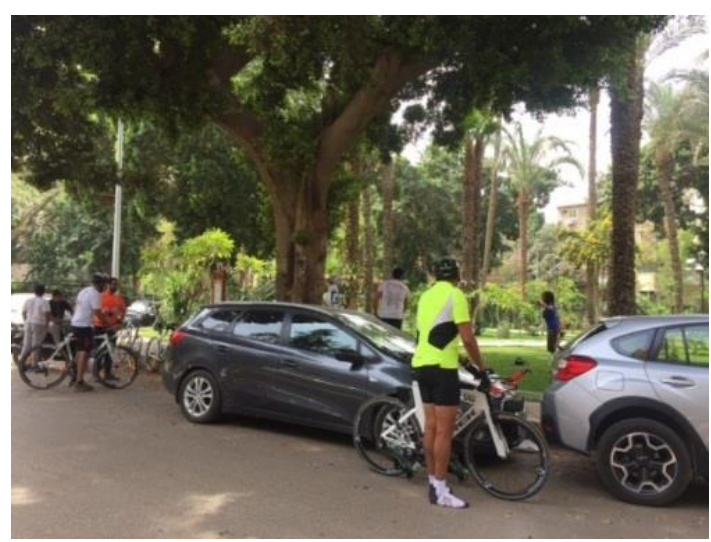

Figure 12 shows some bikers in Mustafa Kamel Squre

(Reference: researcher, 2019)

- Useful, the chosen area shows how the 800 meters radius is including the commercial mixed use street no.9 and metro line, as shown in (figure 13 \&14), as the walkable neighborhoods rely completely on transit, and all the mixed use facilities are located in a comfortable walking distance (5-20 minutes ), close at hand and organized in a way that walking serves the households well.
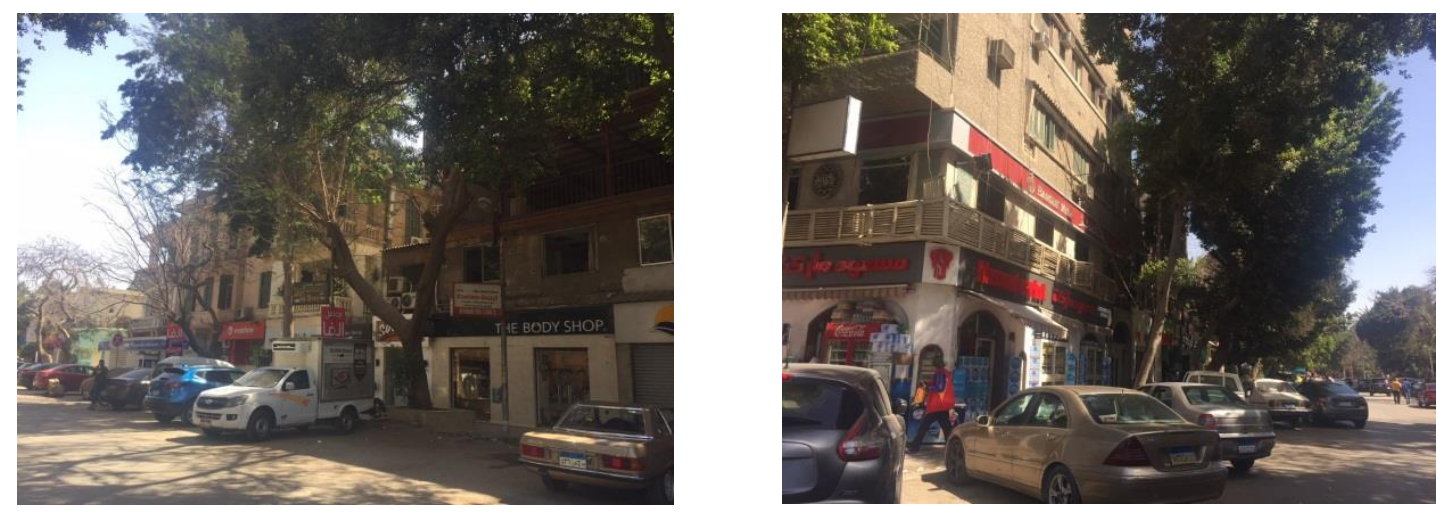

Figure $13 \& 14$ shows the mixed use facilities at street number 9

(Reference: researcher, 2019)

- Comfortable, in the chosen area, the streets and squares are all covered with trees which create enclosures and the squares are full of greenery acting as a cozy and comfy wide open public spaces, specially Mustafa Kamel square, even the abandoned train line in Victoria square creates an interesting urban space that could be rehabilitated later on into an interesting outdoor living room specially that it is filled up with trees, as shown in (figure 15). 


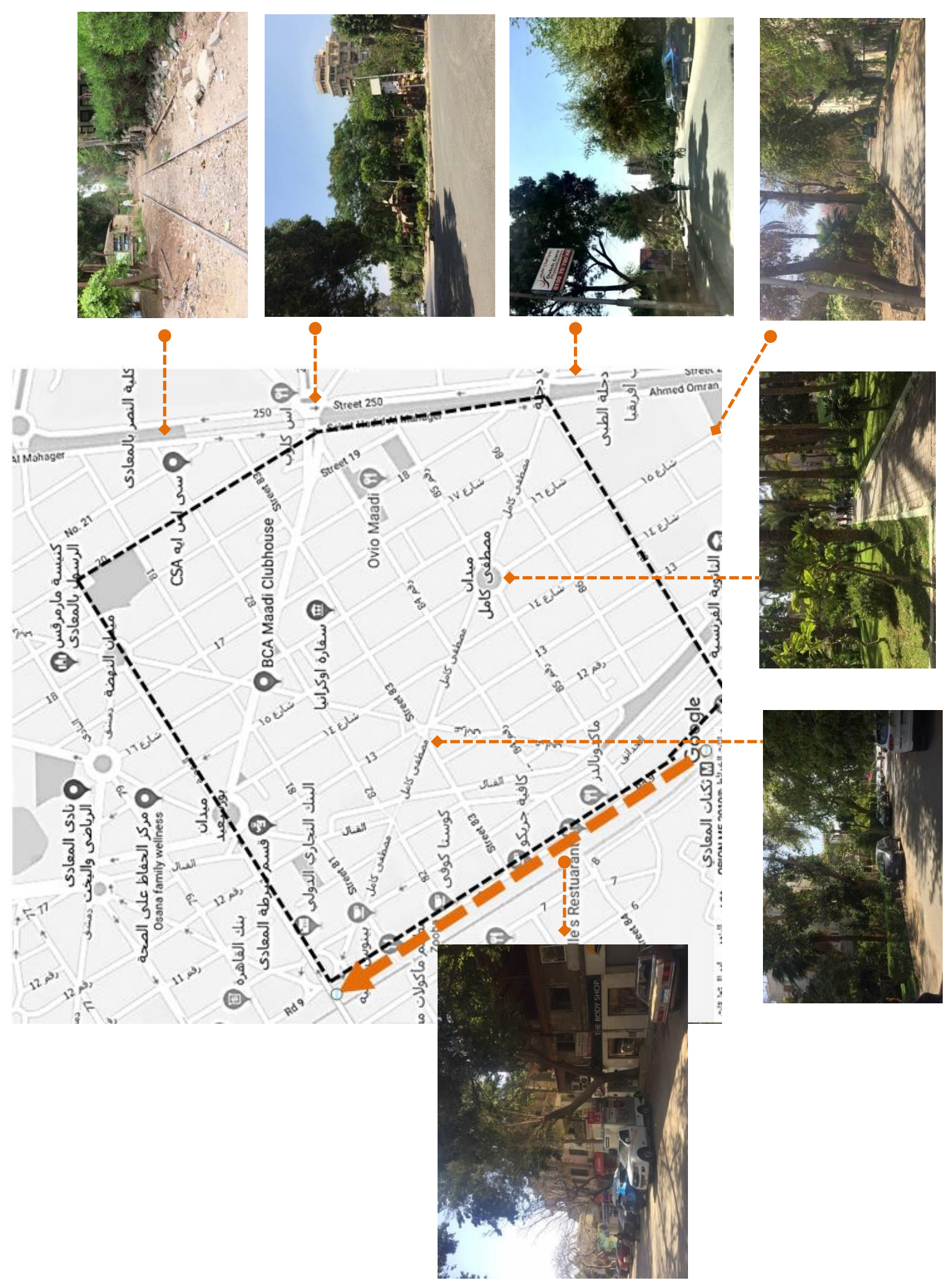

Figure 15 shows how the landscape shape the urban spaces in Maadi

(Reference: Resaercher,2019) 


\subsection{Environmental aspect:}

In the chosen area where as shown above in the attached figures, there are numerous rare valuable plants and many shaded pathways full of trees and shrubs, especially in Mustafa Kamel Square and Street; there is green networks to be enjoyable over time, offering varied visual experiences within shaded green open spaces and pathways. It should be also noted, that Maadians old habit of gardens competeion is still happing till now under the supervion of Mrs. Asmaa el Halwagy the founder of Mohby Ashgar el Maadi NGO. She tends to have a walk every year expolring the original trees and plants in Maadi since it was first planned.This landsacpe discovery tour starts from Mustafa Kamel square and then going through the side streets of Mustafa Kamel Street, which is also located in the chosen area, as shown in figure $(16 \& 17)$. Which proves that the area has plenty of beautiful landscape that should be preserved and explored more frequently.
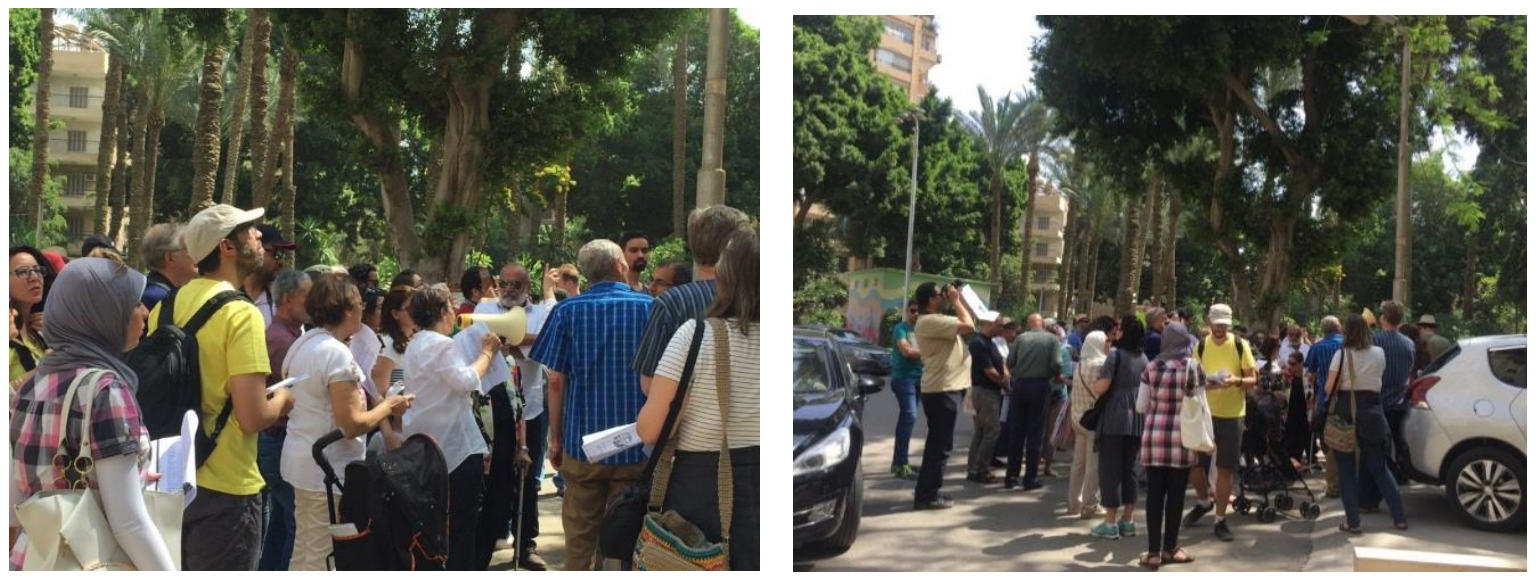

Figure 16 \& 17 show the tour in Mustafa Kamel square under the supervision of Mrs. Halwagy

(Reference: Researcher, 2017)

\section{Conclusion}

Maadi was and sort of still considered a friendly pedestrian neighborhood that should be preserved from the ongoing massive decay to its urban harmony that has been taking place decades ago and especially after the car invasion. Thus, it should be preserved and regenerated by transferring it into walkable neighborhood, as walkability helps in reducing the harmful effect of cars and encourage people to socialize again in its street, which would protect the urban harmony. This will be through enabling walkability steps addressed in the general theory of walkability to act as a catalyst for preserving the neighborhood, which also would strengthen the socio-economic environment and encourage people to walk over driving. As whenever the social bond is disappeared and the streets are lacking of people; the area will be facing deterioration and neglect, which decreases the opportunity of proper conservation and significance of the development of its urban harmony. Therefore, to achieve successful walkable neighborhood, there must be criteria for demarcating the areas to be walkable and would invite walkers, as this plays a 
crucial rule in the success of the procedures. Thus, choosing the area should not be done haphazardly, but rather should follow specific process and fulfill the ten steps of walkability in the general theory of walkability to grantee satisfied results. Accordingly, there should be tools and design elements followed to achieve a walkable neighborhood within the ten steps of walkability, such as; tools targeting the urban planning strategies, architecture rehabilitation, stockholders involved, methods for reducing the car effects, enhancing the economic and management aspects, and adding some street urban elements.

\section{References:}

1- Birabi, A. K. (2007). INTERNATIONAL URBAN CONSERVATION CHARTERS:CATALYTIC OR PASSIVE TOOLS OF URBAN CONSERVATION PRACTICES AMONG DEVELOPING COUNTRIES? . City \& Time 3 (2): 4, 29-53.

2- Myntti, C. ( 2003). Paris along the Nile. cairo: American University in Cairo Press.

3- Speck, J. (2012). Walkable City: How Downtown Can Save America, One Step at a Time.USA: Farrar, Straus and Giroux.

4- Olson. J (2010). The neighbourhood unit: How does Perry's concept apply to modern day planning. Texas : EVstudio Colorado \& Texas Architects \& Engineers.

5- Barton, H., Grant, M.\&Guise, R. (2003). Shaping neighbourhoods: A guide for health, sustainability and vitality. New York: Spon Press.

6- Diyanah Inani Azmia, H. A. (2013). Walking behaviour of Urban and Ruler Residents. The Centre for Environment-Behaviour Studies (cEBs), 98-109.

7- Kimpel, T., Dueker, K., \& El-Geneidy, A. (2007). Using GIS to measure the effect of overlapping service areas on passenger boardings at bus stops. Urban and Regional Information Systems Association Journal, 19(1), 5-11.

8- Frank; et al. 2006. "Many Pathways from Land Use to Health". Journal of the American Planning Association. p. 77.

9- Burden, Dan. "22 Benefits of Urban Street Trees." ufei.org/files/pubs/22benefitsofurbanstreettrees.pdf, May 2006.

10-Raafat, S. (1997, March 2). HISTORY OF MOTORING IN EGYPT. Retrieved July 17, 2016,from EGY.COM : http://www.egy.com/historica/97-03-02.php

11-Raafat,S (2003),"Cairo, the glory years", Harpocrates publishing,Alexandria

12-Stefan Doytchinov, A. S. (2012). Effects of Air Pollution on Materials, Including Historic and Cultural Heritage Monuments. Speciale-CONSERVATION OF CULTURAL HERITAGE , 95-100. Retrieved from Italian National Agency for New Technologies, Energy and Sustainable Economic Development.

13-Ghandour, S. E. (2017). TOWARDS MORE PEDESTRIAN-FRIENDLY STREETS IN CAIRO. PPAD, 1-19.

14-Shoup, D. (2005). The High cost of free parking. Chicago: Planner Press.

15-Mohammad H. Refaat, N. A. (2014). Approaches and Lessons for enhancing walkability in cities:a Landscape Conceptual Solution for Talaat Harb Street, Cairo. International Journal of Education and Research, 301-322.

16-Puttrowait, E. (2014). Encouraging Bicycling as a Means of Sustainable Urban Transportation in Cairo. Cairo: Ain Shams University.

17-Braker, B. (2016). Women in Egypt: The myth of a safe public space. Jane Jacobs 100 Her legacy and relevance in the 21st Century, 243-251. 